\title{
Perbandingan Efektivitas Penghimpunan Dana Wakaf Melalui Uang Berbasis Online di Global Wakaf dan Dompet Dhuafa
}

\author{
Budi Setiadi*, Siska Lis Sulistiani \\ Prodi Hukum Ekonomi Syariah, Fakultas Syariah, Universitas Islam \\ Bandung, Indonesia.
}

*Budis07.bs@gmail.com, Unnufathir@gmail.com

\begin{abstract}
The development of information technology, especially in the field of financial technology helps waqf institutions in the development of waqf findrising strategies, one of which is the existence of online waqf. Therefore it is necessary to optimize the collection of waqf funds based online, one of them with efficiency. The purpose of this study was to determine the level of effectiveness of the collection of waqf-based online waqf funds in Global Waqf and Dompet Dhuafa. The research method used is qualitative with the DEA method. The object of study is the waqf institutions in Global Waqf and Dompet Dhuafa in the form of financial statements of 2 institutions in the period 2016 - 2017, interviews and documentation. Research results based on the above discussion are as follows: (1), Global Waqf and Dompet Dhuafa have fulfilled the elements in raising funds. Both institutions have their respective strategies in collecting funds based on online (2). The level of effectiveness of collecting waqf funds online at Global Waqf and Dompet Dhuafa using the DEA method for the 2016-2017 period, in the 2016 Dompet Dhuafa and Global Waqf levels, the efficiency level has been reaching $100 \%$ or equal to 1 . This shows that Dompet Dhuafa and Global waqf had maximum efficiency in that year. Figures at $0.0 \%$ to gain indicate the efficiency target is in accordance with the actual conditions and obtained achieved 100\%. In 2017 Dompet Dhuafa has an efficiency level of 100\% or equal to 1 . While Global Waqf has decreased efficiency to $50 \%$ due to its value of less than $100 \%$. The optimization of online waqf collection in 2017 at Global Waqf institutions experienced low efficiency in order to achieve perfect efficiency operational costs should be reduced by around $80 \%$, while online waqf receipts must be increased to $49 \%$ of the actual total.
\end{abstract}

Keywords: Financial Technology, Effectiveness, Efficiency, Findrising Strategies, Data Envelopment Analysis.

\begin{abstract}
Abstrak. Adanya perkembangan teknologi informasi khususnya di bidang financial technology membantu lembaga wakaf dalam perkembangan strategi findrising wakaf, salah satunya yaitu dengan adanya wakaf online. Oleh karena itu dibutuhkan optimalisasi penghimpunan dana wakaf berbasis online, salah satunya dengan efisiensi. Tujuan penelitian ini adalah untuk mengetahui tingkat efektivitas penghimpunan dana wakaf berbasis wakaf online di Global Wakaf dan Dompet Dhuafa. Metode Penelitian yang digunakan adalah kualitatif dengan metode DEA. Objek yang diteliti adalah lembaga wakaf di Global Wakaf dan Dompet Dhuafa berupa laporan keuangan 2 lembaga pada periode 2016 - 2017, wawancara dan dokumentasi. Hasil Penelitian berdasarkan pembahasan di atas sebagai berikut : (1), Global Wakaf dan Dompet Dhuafa sudah memenuhi unsur-unsur dalam penghimpunan dana. Kedua lembaga tersebut mempunyai strategi masingmasing dalam menghimpun dana yang berbasis online (2), Tingkat efektivitas penghimpunan dana wakaf online di Global Wakaf dan Dompet Dhuafa dengan metode DEA periode 2016-2017, di periode 2016 Dompet Dhuafa dan Global Wakaf tingkat efisiensi nya sudah mencapai $100 \%$ atau senilai dengan 1 . Hal ini menunjukan Dompet Dhuafa dan Global wakaf sudah efisiensi secara maksimal di tahun tersebut. Angka pada pada to gain $0.0 \%$ menunjukan target efisiensi sudah sesuai dengan kondisi aktual dan memperoleh achieved $100 \%$. Di tahun 2017 Dompet Dhuafa tingkat efisiensinya sudah mencapai 100\% atau senilai dengan 1. Sedangkan Global Wakaf mengalami penurunan efisiensi menjadi $50 \%$ dikarenakan nilainya yang kurang dari $100 \%$. Optimalisasi penghimpunan wakaf online pada tahun 2017 pada lembaga Global wakaf mengalami efisiensi rendah agar mencapai efisiensi sempurna biaya operasional harus dikurangi sekitar $80 \%$, sedangkan penerimaan wakaf online harus dinaikan menjadi $49 \%$ dari total actualnya.
\end{abstract}

Kata Kunci: Financial Technology, Efektivitas, Efisiensi, Strategi Findrising, Data Envelopment Analysis 


\section{A. Pendahuluan}

\section{Latar Belakang Masalah}

Wakaf telah lama dikenal sebagai salah satu bentuk filantropi Islam dan peruntukkannya tidak hanya terbatas dibidang keagamaan, tetapi juga pendidikan, sosial, pertanian, hingga layanan kesehatan. Wakaf pun menjadi salah satu bentuk distribusi kekayaan non-pasar untuk menciptakan pemerataan keadilan sosial di tengah masyarakat. Tetapi selama ini kebanyakan umat Islam, khususnya Indonesia, memahami wakaf hanya sebatas pemberian berbentuk barang tidak bergerak seperti tanah dan bangunan. Karena itu, wakaf di Indonesia pada umumnya digunakan untuk membangun mesjid, musholla, kuburan, pondok pesantren, rumah yatim piatu, dan madrasah. Padahal wakaf telah mengalami perkembangan, dan tampil dalam wujud lain, diantaranya wakaf produktif dan wakaf tunai.

Adanya perkembangan teknologi informasi khususnya dibidang financial technology yang begitu pesat tentunya berkontribusi membantu lembaga pengelola wakaf dalam perkembangan wakaf. Financial technology atau yang sering dikenal dengan istilah fintech merupakan hasil gabungan antara jasa keuangan dengan teknologi yang akhirnya mengubah model bisnis dari konvensional menjadi moderat, yang awalnya dalam sebuah transaksi/akad harus bertatap-muka dan membawa sejumlah uang tunai, kini dapat melakukan transaksi jarak jauh dengan melakukan pembayaran yang dapat dilakukan dalam hitungan detik saja. Fintech muncul seiring perubahan gaya hidup masyarakat yang saat ini didominasi oleh pengguna teknologi informasi tuntutan hidup yang serba cepat.

Tidak sedikit lembaga pengelolaan wakaf yang melakukan pembaharuan dengan memanfaatkan perkembangan teknologi tersebut seperti layanan sedekah online, zakat online hingga wakaf online. Sebelum adanya wakaf online, waqif berwakaf dengan system wakaf offline, namun banyak kekurangan dari wakaf offline tersebut, seperti waqif berwakaf dengan cara harus datang ke tempat lembaga yang mereka imginkan, selain itu wakaf offline dapat menyita waktu dan tenaga. Seperti yang kita ketahui bahwa dengan adanya perkembangan teknologi, lembaga-lembaga findrising wakaf seperti Global Wakaf dan Dompet Dhuafa mengeluarkan system agar orang yang berwakaf dapat mudah untuk melakukan wakafnya, dengan meluncurkan system yang dinamakan wakaf online. Dengan wakaf online kita tidak perlu datang ke tempat lembaga untuk berwakaf, kita hanya perlu membuka website lembaga tersebut dan mengikuti alur yang sudah ada. Dengan wakaf online kita juga bisa berwakaf dimana saja, dan tentu dengan wakaf online kita dapat menghemat waktu dan biaya.

Salah dua lembaga yang mengelola harta wakaf dengan findrising online adalah Global Wakaf Aksi Cepat Tanggap dan Dompet Dhuafa. Penghimpunan dana wakaf di Global Wakaf dapat melalui media online seperti website ACT, e-commerse (Bukalapak, Blibli, Tokopedia, Elevenia) dan crowdfunding Kitabisa.com. setiap harinya transaksi donasi melalui ACT paling sepi bisa mencapai 1.000 lebih transaksi. Apabila sedang menggelar program unggulan transaksi bisa mencapai 5.000 lebih. 60 persen transaksi dilakukan manual dan 40 persen transaksi dilakukan online. Karena kecenderungan bertransaksi via online saat ini mulai tinggi. Ke depannnya, setiap transaksi akan diarahkan via website dan mitra-mitra online. Penerimaan dana wakaf pada tahun 2017 sebesar 293.769.378, 40\% penerimaan berasal dari media online, sehingga penerimaan dana wakaf dari media online sebesar Rp.117.507.751. Selain Global Wakaf ACT, Penghimpunan dana wakaf di Dompet Dhuafa juga dapat melalui media online seperti website Dhompet Dhuafa, platform e-commerce seperti Tokopedia, Bukalapak DANA, OVO, Shopee, Blibli.com, Lazada, Belanja.com, Duniahalal.com, Bawaberkah.org hingga Elevenia. Penghimpunan dana melalui e-commerce, terus mengalami peningkatkan trafik penghimpunan. $40 \%$ transaksi dilakukan secara manual dan $60 \%$ transaksi dilakukan online. Penerimaan dana wakaf pada tahun 2017 sebesar Rp.20.004.000, 60\% penerimaan berasal dari media online, sehingga penerimaan wakaf dari media online sebesar Rp.12.002.400.

\section{Tujuan Penelitian}

Berdasarkan uraian latar belakang di atas, maka tujuan penelitian ini adalah sebagai berikut:

1. Mengetahui efektivitas findriising wakaf yang berbasis online di Global Wakaf ACT dan Dompet Dhuafa.

2. Mengetahui efektivitas findrising wakaf di Global Wakaf ACT dan Dompet Dhuafa. 


\section{B. Landasan Teori}

\section{Tinjauan Umum Efektivitas}

Kata efektif berasal dari bahasa inggris effective artinya berhasil, sesuatu yang dilakukan berhasil dengan baik. Konsep efektivitas merupakan konsep yang luas, mencakup berbagai faktor di dalam maupun di luar organisasi. Efektivitas juga dapat diartikan sebagai ukuran berhasil tidaknya suatu organisasi mencapai tujuannya. Apabila suatu organisasi berhasil mencapai tujuannya, maka organisasi tersebut dikatakan telah berjalan dengan efektif.

\section{Tinjauan Umum Penghimpunan Dana}

Penghimpunan dana dalam kamus Indonesia-Inggris adalah Fund-Raising, sedangkan orang yang mengumpulkan dana disebut Fand-Raiser. Sedangkan dalam kamus Besar Bahasa Indonesia, yang dimaksud dengan pengumpulan adalah proses, cara, perbuatan mengumpulkan, penghimpunan, pengerahan.

Penghimpunan adalah proses mempengaruhi masyarakat untuk berwakaf dan dalam pelaksanaannya meliputi unsur-unsur berikut: Analisis kebutuhan, segmentasi, identifikasi profil wakif, produk, harga biaya transaksi, dan promosi.

1. Analisis kebutuhan

Analisis kebutuhan meliputi: Kesesuaian dengan syariat, Laporan dan pertanggung jawaban, Manfaat bagi kesejahteraan umat, Pelayanan yang berkualitas \Silaturrahmi dan komunikasi

2. Segmentasi Calon Wakif/ Donatur

Segmentasi wakif sesuai undang-undang adalah perorangan, organisasi, dan lembaga berbadan hukum. Tetapi di lihat dari sudut pandang geografis juga dapat dilakukan misalnya dengan sigmentasi lokal, regional, nasional, dan internasional. Di lihat dari sudut pandang demografis misalnya menurut jenis kelamin, kelompok usia, status perkawinan, dan ukuran keluarga, Selanjutnya secara psikologis misalnya status ekonomi, pekerjaan, gaya hidup, hoby, dll.

3. Identifikasi Profil Donatur/ calon wakif

Dalam hal ini sangat penting untuk mengetahui profil calon wakif maupun calon donator serta biaya operasional pengelolaan harta benda wakaf. Profil calon wakif perseorangan dapat berbentuk biodata atau $\mathrm{CV}$, untuk calon wakif organisasi atau lembaga hukum dalam bentuk company profile lembaga.

4. Produk

Nazhir seyogyanya mempunyai satu atau beberapa produk wakaf sesui perundangan yang akan ditawarkan kepada para calon wakif. Produk ini mengacu kepada peruntunan wakaf sesuai perundang-undangan yang berlaku. Berdasarkan uraian diatas nazhir yang akan melakukan penghimpunan mengajak masyarakat untuk berwakaf, kemudian dana wakaf yang terhimpun akan dikelola oleh Manajer Investasi Syariah, seperti deposito, reksadana, obligasi yang manfaatnya akan digunakan untuk aktivitas pemberdayaan masyarakat yang membutuhkan.

5. Harga

Harga dimaksudkan besaran nilai harta benda yang akan diwakafkan atau kemampuan nazhir untuk mengelolanya. Misalnya untuk Badan Wakaf Indonesia (BWI) sebagai nazhir, dalam wakaf tunai dengan Lembaga Keuangan Syariah (LKS) di empat Bank Syariah telah disepakati minimal dengan harga/ nilai dua ratus lima puluh ribu rupiah sampai satu juta rupiah dan seterusnya calon wakif dapat melaksanakan ikrar wakaf uang.

Dari penjelasan diatas dapat disimpulkan bahwa pengertian penghimpunan sudah dilakukan secara benar dengan melibatkan semua unsur-unsur yang berkaitan dengan tata cara penghipunan dana wakaf uang.

\section{Konsep Wakaf Melalui Online}

Kata "wakaf" dalam bahasa Indonesia berasal dari kata dalam bahasa Arab yaitu 'al-waqf' dari 
kata waqafa-yaqifu-waqfan, yang berarti menahan atau menghentikan. Kata lain yang sering digunakan sinonim dengan wakaf adalah al-hubu (jamaknya al-ahbas) dari kata habasayahbisu-tahbisan, yang berarti sesuatu yang ditahan atau dihentikan, maksudnya ditahan pokoknya dan dimanfaatkan hasilnya dijalan Allah. Kata "wakaf" dalam hukum Islam mempunyai dua arti: arti kata kerja, ialah tindakan mewakafkan, dan arti kata benda, yaitu obyek tindakan mewakafkan. Sedangkan wakaf menurut istilah syara' adalah menahan harta yang mungkin diambil manfaatnya tanpa menghabiskan atau merusak bendanya (ainnya) dan digunakan untuk kebaikan.

Wakaf online merupakan salah satu cara atau strategi yang ditawarkan oleh lembaga ZISWAF untuk masyarakat yang ingin berwakaf yaitu dengan menggunakan sistem online atau dengan kata lain wakaf yang transaksinya dilakukan secara online (elektronik) oleh siapa saja dan di mana saja yang berniat ingin berwakaf. Financial technology merupakan bagian dari sarana kemajuan teknologi yang dapat disinergikan dengan fundraising wakaf mengingat di era milenial ini, sebagian besar transaksi finansial digunakan melalui proses berbasis internet. Kemudahan yang ditawarkan dalam financial technology menjadi daya Tarik tersendiri untuk memudahkan semua pihak khususnya dalam penghimpunan dana dalam program wakaf uang di Indonesia. Masyarakat dapat menyalurkan dana wakaf dengan mengakses websitenya yaitu dengan media teknologi baik smartphone maupun PC (Personal Computer) dan sambungan internet. Kebolehan wakaf online dengan mensyaratkan terjaminnya harta wakaf dari persengketaan dan terdistribusinya hasil wakaf kepada yang berhak. Untuk mencapai tujuan itu diperlukan lembaga perwakafan yang sarat akan teknologi, transparan, dan akomodatif terhadap perkembangan kebutuhan masyarakat. Wakaf online ini didukung oleh payung hukum yang jelas, manajemen yang baik dan rethinking terhadap inovasi dari ikrar wakaf. Misi utama dari gerakan waqaf online adalah untuk mengajak seluruh pihak dimanapun mereka berada, untuk turut terlibat dan peduli terhadap sesama. Diantara harta wakaf yang dapat dihimpun dengan wakaf online adalah harta yang berupa uang/wakaf uang dan wakaf melalui uang. Wakaf uang, menjadikan uang sebagai obyek wakaf yang bernilai tetap, menjadi modal usaha produktif dan keuntungannya didistribusikan kepada mauquf 'alaih (penerima manfaat). Wakaf melalui uang, wakaf uang yang akan diwujudkan menjadi obyek wakaf tertentu yang ditetapkan oleh wakif.

\section{Hasil Penelitian dan Pembahasan}

Analisis pelaksanaan penghimpunan dana wakaf berbasis online di Global Wakaf dapat melalui website dan e-commerce. Fundraising wakaf sudah memenuhi unsur-unsur dalam penghimpunan dana yang mana tujuan awal bukan mencari dana sebanyak-banyaknya, namun mengutamakan citra dan manfaat umat, sehingga muncul kepercayaan pada wakif untuk terus berwakaf. Sedangkan Dompet Dhuafa telah melakukan fundraising wakaf berbasis online, yang mana dapat menggunakan website, e-money dan e-commerce. Melalui metode ini, wakif dapat mudah melakukan wakaf, kapan saja dan dimana saja. terbukti dengan meningkatnya penghimpunan dana wakaf yang masuk. selain itu, metode fundraising wakaf sudah memenuhi unsur-unsur dalam penghimpunan dana.

Tingkat efektivitas penghimpunan dana wakaf online di Global Wakaf dan Dompet Dhuafa dengan metode DEA periode 2016-2017, adalah periode 2016 Dompet Dhuafa dan Global Wakaf tingkat efisiensi nya sudah mencapai $100 \%$ atau senilai dengan 1 . Hal ini menunjukan Dompet Dhuafa dan Global wakaf sudah efisiensi secara maksimal di tahun tersebut. Angka pada pada to gain $0.0 \%$ menunjukan target efisiensi sudah sesuai dengan kondisi aktual dan memperoleh achieved $100 \%$. Di tahun 2017 Dompet Dhuafa tingkat efisiensinya sudah mencapai $100 \%$ atau senilai dengan 1 . Sedangkan Global Wakaf mengalami penurunan efisiensi menjadi $50 \%$ dikarenakan nilainya yang kurang dari $100 \%$. Optimalisasi penghimpunan wakaf online pada tahun 2017 pada lembaga Global wakaf mengalami efisiensi rendah agar mencapai efisiensi sempurna biaya operasional harus dikurangi sekitar $80 \%$, sedangkan penerimaan wakaf online harus dinaikan menjadi $49 \%$ dari total actualnya.

\section{Kesimpulan}

Berdasarkan uraian hasil penelitian dan analisis pembahasan serta sesuai dengan tujuan 
penelitian, maka simpulan dari penelitian ini adalah sebagai berikut:

1. Analisis pelaksanaan penghimpunan dana wakaf berbasis online di Global Wakaf dapat melalui website dan e-commerce. Fundraising wakaf sudah memenuhi unsur-unsur dalam penghimpunan dana yang mana tujuan awal bukan mencari dana sebanyakbanyaknya, namun mengutamakan citra dan manfaat umat, sehingga muncul kepercayaan pada wakif untuk terus berwakaf. Sedangkan Dompet Dhuafa telah melakukan fundraising wakaf berbasis online, yang mana dapat menggunakan website, e-money dan e-commerce. Melalui metode ini, wakif dapat mudah melakukan wakaf, kapan saja dan dimana saja. terbukti dengan meningkatnya penghimpunan dana wakaf yang masuk. selain itu, metode fundraising wakaf sudah memenuhi unsur-unsur dalam penghimpunan dana.

2. Tingkat efektivitas penghimpunan dana wakaf online di Global Wakaf dan Dompet Dhuafa dengan metode DEA periode 2016-2017, adalah periode 2016 Dompet Dhuafa dan Global Wakaf tingkat efisiensi nya sudah mencapai $100 \%$ atau senilai dengan 1 . Hal ini menunjukan Dompet Dhuafa dan Global wakaf sudah efisiensi secara maksimal di tahun tersebut. Angka pada pada to gain $0.0 \%$ menunjukan target efisiensi sudah sesuai dengan kondisi aktual dan memperoleh achieved $100 \%$. Di tahun 2017 Dompet Dhuafa tingkat efisiensinya sudah mencapai $100 \%$ atau senilai dengan 1. Sedangkan Global Wakaf mengalami penurunan efisiensi menjadi $50 \%$ dikarenakan nilainya yang kurang dari $100 \%$. Optimalisasi penghimpunan wakaf online pada tahun 2017 pada lembaga Global wakaf mengalami efisiensi rendah agar mencapai efisiensi sempurna biaya operasional harus dikurangi sekitar $80 \%$, sedangkan penerimaan wakaf online harus dinaikan menjadi $49 \%$ dari total actualnya.

\section{Daftar Pustaka}

[1]. AksiCepatTanggap, (2019, Desember). "berdonasi di act kini semakin mudah" dalam https://news.act.id/

[2]. Dompetdhuafa, (2019, Desember). "Dompet Dhuafa Tembus Penghimpunan Rp. 96 Milyar: Bukti Semangat Jangan Takut Berbagi Masyarakat Indonesia” dalam https://www.dompetdhuafa.org/

[3]. Tika, Moh. Pabundu. (2014). Budaya Organisasi dan Peningkatan Kinerja Perusahaan, Jakarta: Bumi Aksara.

[4]. Garnida Agus, Junni Donni. (2013). Manajemen Perkantoran Efektif, Efisien, dan Profesional, Bandung: Alfabeta.

[5]. Salim, Petter. (2013). Salim's Nith Collegiate English-Indonesia Dictionary. Jakarta: Erlangga.

[6]. Departemen Pendidikan dan kebudayaan, "Kamus Besar Bahasa Indonesia", Cet. Ke-9.

[7]. Suparman IA, Bendahara Badan Wakaf Indonesia," Manajemen Fundraising Dalam Penghimpunan Harta Wakaf " (Bagian 1), dari (http.bw- indonesia.net)

[8]. Sulistiani, Lis Siska. (2017). Pembaruan Hukum Wakaf di Indonesia. Bandung: PT Refika Aditama.

[9].

(2019). “Aspek Hukum Fintech Syariah Untuk Peningkatan Findrising Wakaf Uang Di Indonesia”. Jurnal Ilmu Syariah, Perundang-undangan dan Ekonomi Islam Volume 11 Edisi 1.

[10].https://www.globalwakaf.com/ Desember 2019 